\title{
Utilização de azul de metileno para investigar a capacidade adsortiva de biomassas
}

\author{
Use of methylene blue to investigate the adsorptive capacity of biomass \\ Uso de azul de metileno para investigar la capacidad de adsorción de la biomasa
}

Recebido: 19/10/2021 | Revisado: 26/10/2021 | Aceito: 27/10/2021 | Publicado: 31/10/2021

\author{
Matheus Campos Castro \\ ORCID: https://orcid.org/0000-0002-9918-1491 \\ Universidade Estadual de Maringá, Brasil \\ E-mail: 1996mcastro@gmail.com \\ Eloize Silva Alves \\ ORCID: https://orcid.org/0000-0002-3340-8374 \\ Universidade Estadual de Maringá, Brasil \\ E-mail: eloizeetaus@gmail.com \\ Bruno Henrique Figueiredo Saqueti \\ ORCID: https://orcid.org/0000-0002-1118-4605 \\ Universidade Estadual de Maringá, Brasil \\ E-mail: bruno_saqueti@outlook.com \\ Silvana Fernandes Montanher \\ ORCID: https://orcid.org/0000-0002-9421-8507 \\ Universidade Tecnológica Federal do Paraná, Brasil \\ E-mail: silvanafm@utfpr.edu.br
}

\begin{abstract}
Resumo
O presente trabalho tem como objetivo avaliar a capacidade de adsorção de biomassas, bagaço de laranja (Citrus Sinensis), serragens de Pinus elliotti e Mezilaurus itaúba e cascas de ovos frente ao corante azul de metileno, além de avaliar a montagem do empacotamento da coluna, e após isso verificar se o processo de dessorção foi possível de ser realizado. Para isso os estudos de adsorção foram realizados em coluna de leito fixo utilizando como adsorvente, bagaço de laranja, serragem pinus elliotti, serragem mezilaurus itaúba e cascas de ovos, o processo de adsorção foi realizado como solução extratora ácido clorídrico $1,0 \mathrm{~mol} \mathrm{~L}^{-1}$. Foi possível observar que utilizando como adsorvente as cascas de ovos, a adsorção era lenta $\left(0,02 \mathrm{~mL} \mathrm{~min}^{-1}\right)$, e o processo de adsorção não ocorria, já as demais biomassas o processo de adsorção aconteceu, sendo que a biomassa que apresentou melhor valor foi o bagaço de laranja, apresentando capacidade máxima de adsorção de $63 \mathrm{mg} \mathrm{g}^{-1}$, sendo que a serragem pinus elliotti e itaúba apresentaram 29,0 e $15,6 \mathrm{mg} \mathrm{g}^{-1}$ respectivamente. O processo de dessorção foi viável quando utilizando-se como adsorvente ambas as serragens, porém utilizando-se o bagaço de laranja o mesmo não foi observado, pois o processo de dessorção se tornou extremamente lento, cerca de $5 \mathrm{~mL} \mathrm{~h}^{-1}$, impossibilitando o estudo desse parâmetro. Com isso foi possível concluir que a melhor biomassa testada, foi o bagaço de laranja, ou seja, a qual apresenta a maior capacidade adsortiva para o corante azul de metileno.
\end{abstract}

Palavras-chave: Adsorção; Azul de metileno; Biomassas; Corantes.

\begin{abstract}
The present work aims to evaluate the adsorption capacity of biomass, orange bagasse (Citrus Sinensis), Pinus elliotti and Mezilaurus itaúba sawdust and eggshells against methylene blue dye, in addition to evaluating the assembly of the column packing, and after that, check if the desorption process was possible to be carried out. For this, the adsorption studies were carried out in a fixed bed column using orange bagasse, pinus elliotti sawdust, mezilaurus itaúba sawdust and eggshells as adsorbent. It was observed that using eggshells as an adsorbent, adsorption was slow $\left(0.02 \mathrm{~mL} \mathrm{~min}^{-}\right.$ ${ }^{1}$ ), and the adsorption process did not occur, as for the other biomasses the adsorption process took place, and the biomass that presented best value was the orange bagasse, with a maximum adsorption capacity of $63 \mathrm{mg} \mathrm{g}^{-1}$, and the sawdust pinus elliotti and itaúba presented 29.0 and $15.6 \mathrm{mg} \mathrm{g}^{-1}$, respectively. The desorption process was feasible when using both sawdust as adsorbent, but using orange pomace it was not observed, as the desorption process became extremely slow, about $5 \mathrm{~mL} \mathrm{~h}^{-1}$, making it impossible to study of this parameter. Thus, it was possible to conclude that the best tested biomass was orange bagasse, that is, which has the highest adsorption capacity for the methylene blue dye.
\end{abstract}

Keywords: Adsorption; Methylene blue; Biomass; Dyes.

\section{Resumen}

El presente trabajo tiene como objetivo evaluar la capacidad de adsorción de biomasa, bagazo de naranja (Citrus Sinensis), aserrín de Pinus elliotti y Mezilaurus itaúba y cáscaras de huevo frente al colorante azul de metileno, además de evaluar el ensamblaje del empaque de la columna, y luego verificar si el Se pudo realizar el proceso de 
desorción. Para ello, los estudios de adsorción se realizaron en una columna de lecho fijo utilizando bagazo de naranja, aserrín de pinus elliotti, aserrín de mezilaurus itaúba y cáscaras de huevo como adsorbente. Se observó que utilizando cáscaras de huevo como adsorbente, la adsorción fue lenta $\left(0.02 \mathrm{~mL} \mathrm{~min}^{-1}\right)$, y el proceso de adsorción no ocurrió, ya que para las otras biomasas se realizó el proceso de adsorción, y la biomasa que presentó mejor valor fue la naranja. el bagazo, con una capacidad máxima de adsorción de $63 \mathrm{mg}$ g-1, y el aserrín pinus elliotti e itaúba presentaron 29.0 y $15.6 \mathrm{mg} \mathrm{g}^{-1}$, respectivamente. El proceso de desorción fue factible al utilizar tanto aserrín como adsorbente, pero con orujo de naranja no se observó, ya que el proceso de desorción se volvió extremadamente lento, alrededor de $5 \mathrm{~mL} \mathrm{~h}^{-1}$, imposibilitando el estudio de este parámetro. Así, se pudo concluir que la biomasa mejor probada fue el bagazo de naranja, es decir, que tiene la mayor capacidad de adsorción para el colorante azul de metileno.

Palabras clave: Adsorción; Azul de metileno; Biomasa; Tintes.

\section{Introdução}

As indústrias têxteis têm elevada importância na economia brasileira, sendo que durante a parte final do processo, ao tingimento e acabamento, necessitam de um volume de água muito elevado e também geram muitos resíduos poluentes, contendo cor característica e compostos químicos tóxicos ao ser humano e ao meio ambiente (Hassemer, \& Sens, 2002; Fujisawa \& Lamas, 2011). E um dos grandes obstáculos em tratar estes efluentes, está na existência de grandes quantidades de compostos orgânicos que são poucos biodegradáveis e de estrutura molecular muito complexa entre elas se destacam os corantes e surfactantes (Silva, Gonçalves, \& Abud, 2016).

Efluentes do processo industrial na etapa de tingimento, os corantes utilizados são em sua maioria altamente poluente, e grande parte desses efluentes se despejados de forma irregular traz um dos maiores problemas ambientais. O maior desafio da indústria têxtil é em reduzir a cor e a turbidez destes efluentes, para desta forma atender as regulamentações ambientais (Oliveira et al., 2014).

Existem muitas metodologias que podem ser empregadas no tratamento de efluentes, utilizando técnicas de troca iônica, extração por solventes, osmose reversa e adsorção (Minatti, 2020). As metodologias desenvolvidas devem ser de fácil manuseio e operação e altamente eficiente, buscando um baixo custo, e que gere o mínimo de resíduo secundário (Behera, Nayak, Banerjee, Chakrabortty, \& Tripathy, 2021). Sendo que dessas metodologias a que tem sido empregada com maior sucesso na remoção dos corantes é a adsorção, este processo tem uma ampla aplicação industrial, pois une baixo custo e elevadas taxas de remoção, sendo que em alguns casos é possível a recuperação do corante pois é um método não destrutivo (Madhav, Ahamad, Singh, \& Mishra, 2018), o adsorvente mais eficiente e popular é o carvão ativado, contudo seu elevado custo restringe seu uso (Cunico, Magdalena, Carvalho, \& Fungaro, 2009).

Nesse contexto, a utilização de biomassa residual tem gerado grande interesse para a remoção de poluentes dos efluentes aquosos por adsorção, a biomassa é um produto natural, altamente biodegradável de baixíssimo custo, e que apresenta propriedades adsortivas de poluentes, sejam orgânicos ou inorgânicos (Adeyiga, Hu, \& Greer, 1998; Muharrem \& Ince, 2017; Giannakoudakis et al., 2018).

O fenômeno de adsorção se difere da absorção, pois o mesmo só ocorre na superfície do material, nada é absorvido, geralmente em algumas situações corriqueiras é difícil avaliar qual processo ocorreu o de absorção ou adsorção, sendo assim geralmente denominado somente que houve sorção (Matiello, 2017). No entanto no caso dos fenômenos que envolvem o carvão sempre se sobressai o fenômeno de adsorção (Matiello, 2017), na qual pode ocorrer por dois tipos de interação: físissorção (adsorção física) e a quimissorção (adsorção química). A maneira com a qual a distinção de qual interação de adsorção ocorreu pode ser atribuído à natureza e intensidade das interações que ocorre entre a substância que adsorve, chamado de adsorvente, e a substância que é adsorvida, chamada de adsorvato. Na adsorção física, a interação entre as duas substâncias ocorre por forças intermoleculares do tipo van der Waals (interação de dispersão ou dipolo induzido, comumente chamado de forças de London, e a interação dipolo-dipolo) (Abd, Naji, Hashim, \& Othman, 2020; Tony, 2020). 
$\mathrm{Na}$ quimissorção, a interação das substâncias ocorre por meio das ligações químicas, que em sua maioria são covalentes, e que tendem a um número máximo de coordenação com o substrato. Os valores de entalpia para cada tipo de adsorção também são bem distintos sendo o da adsorção física entre $20 \mathrm{~kJ} \mathrm{~mol}^{-1}$, e o da adsorção química é de uma ordem 10 vezes maior $200 \mathrm{~kJ} \mathrm{~mol}^{-1}$ (Atkins \& Paula, 1997). Contudo na maior parte das vezes as duas adsorções ocorrem simultaneamente, portanto, é mais adequado descrever o processo de adsorção como uma combinação entre os dois tipos de interação (Guilarduci, Mesquita, Martelli, \& Gorgulho, 2006).

O composto orgânico azul de metileno é um corante catiônico que pertence a classe das fenotiazinas, tem grandes aplicações nas áreas químicas e médicas, já foi utilizado diversas vezes para testar as propriedades adsortivas de carvões ativados, e também na determinação da área superficial de diferentes tipos de adsorventes, e recentemente vem sendo utilizado em estudos de adsorção com adsorventes alternativos (Rafatullah, Sulaiman, Hashim, \& Ahmad, 2010). Diante o exposto, o presente trabalho tem como objetivo avaliar a capacidade de adsorção de biomassas, bagaço de laranja (Citrus Sinensis), serragens de Pinus elliotti e Mezilaurus itaúba e cascas de ovos frente ao corante azul de metileno, além de avaliar a montagem do empacotamento da coluna, e após isso verificar se o processo de dessorção foi possível de ser realizado.

\section{Metodologia}

O design selecionado para o presente estudo foi laboratorial e cientifico (Pereira, Shitsuka, Parreira, \& Shitsuka, 2018).

\subsection{Preparação dos adsorventes}

Utilizou-se quatro tipos de adsorventes: casca de ovos, dois tipos diferentes de serragem (Pinus elliotti e Mezilaurus itaúba) e o bagaço da laranja (Citrus Sinensis). Os ovos e laranjas foram adquiridos em mercados locais, assim como as serragens foram doadas por uma madeireira da cidade. As cascas de ovos brancos de galinha foram obtidas após retirada da gema e clara, em seguida secas ao sol e trituradas em liquidificador, em seguida foram peneiradas em peneira de $425 \mu \mathrm{m}$. Os dois tipos de serragem foram somente peneirados em peneira de $425 \mu \mathrm{m}$. O bagaço de laranjas da variedade pera foi obtido após as mesmas serem descascadas e em seguida somente a polpa, foi triturada em liquidificador e lavados em água corrente até a completa remoção de coloração. Em seguida o material foi seco em estufa com circulação de ar a $60{ }^{\circ} \mathrm{C}$ por 10 horas e peneirado em peneira de $425 \mu \mathrm{m}$ e $600 \mu \mathrm{m}$ (Castro, Alves, Saqueti, \& Montanher, 2021).

\subsection{Estudos da adsorção e dessorçãa.}

Os ensaios de adsorção foram realizados em sistema de coluna de leito fixo usando coluna cromatográfica com torneira de vidro e placa porosa $(15 \times 200 \mathrm{~mm})$.

A primeira etapa no estudo foi otimizar a melhor maneira de preparar a coluna, com a massa adequada de adsorvente e a concentração adequada da solução de azul de metileno. Utilizou-se quatro metodologias para montagem do leito para a passagem do corante.

A primeira foi apenas colocar-se uma quantidade de adsorvente na coluna e passar o líquido.

A segunda foi utilizada algodão antes de colocar o adsorvente na coluna e logo após passar o líquido.

A terceira foi colocar algodão por cima do adsorvente e em seguida a passagem do líquido.

E a quarta foi a utilização de perolas de vidro em cima do adsorvente utilizado e a passagem do líquido em seguida.

Após determinado a metodologia para a passagem do adsorvente, que foi a quarta metodologia testada, foi realizado o empacotamento da coluna como proposto por Castro, Alves, Saqueti, \& Montanher (2021), utilizando diferentes massas de 
adsorventes, para as cascas de ovos, serragem de Pinus elliotti e Mezilaurus itaúba foi utilizado 1,5 g e para o bagaço de laranja $0,7 \mathrm{~g}$.

A solução de azul de metileno $\left(50 \mathrm{mg} \mathrm{L}^{-1}\right)$ foi percolada nas colunas e recolhidas em provetas de $25 \mathrm{~mL}$. A concentração de azul de metileno remanescente nas alíquotas recolhidas foi determinada em espectrofotômetro UV-VIS da PerkinElmer usando cubetas de vidro. Foi construído uma curva de saturação de volume percolado do adsorvente por $\mathrm{Cv} / \mathrm{Ci}$. No qual Ci é a concentração de entrada na coluna, ou seja $50 \mathrm{mg} \mathrm{L}^{-1}$, e Cv é a concentração de saída da coluna.

A curva de calibração foi obtida na faixa de concentração de 2 a $10 \mathrm{mg} \mathrm{L}^{-1}$ diluindo a solução estoque de $1,0 \mathrm{~g} \mathrm{~L}^{-1}$.

Os estudos de dessorção foram realizados usando solução de ácido clorídrico $(\mathrm{HCl})$ 1,0 mol L-1 como solução extratora. Após a saturação do adsorvente com azul de metileno o $\mathrm{HCl}$ foi percolado para acontecer o processo de dessorção e alíquotas de $25 \mathrm{~mL}$ foram recolhidas usando uma proveta. As curvas de dessorção foram construídas utilizando o volume de $\mathrm{HCl}$ que correu pela coluna pela concentração do corante extraído $\left(\mathrm{mg} \mathrm{L}^{-1}\right)$

\subsection{Estudos da vazão}

O estudo da vazão foi realizado empacotando-se a coluna com bagaço de laranja (Citrus Sinensis) com diferentes massas $(2,1,5,1,25,1,0$ e 0,7$)$, em seguida percolado a amostra de azul de metileno, e anotado o tempo que demorava para 25 $\mathrm{mL}$ de amostra passar pela coluna, em seguida foi realizada uma média do volume pelo tempo demorado. Esta análise foi realizada em triplicata.

\subsection{Análise estatística}

Os dados da análise de vazão foram submetidos à análise de variância (ANOVA) e teste de Tukey $(\mathrm{p}<0,05)$, utilizando o software Assistat.

\section{Resultados e Discussão}

Para a quantificação do azul de metileno foram obtidas curvas de calibração usando o comprimento de onda máximo $\left(\lambda_{\max }\right)$ de $665 \mathrm{~nm}$. A Figura 1 mostra uma dessas curvas, o coeficiente de correlação $\left(\mathrm{R}^{2}\right)$ próximo de 1,0 , mostra a boa correlação dos dados na faixa de concentração estudada. 
Figura 1. Curva de calibração para a determinação de azul de metileno $\left(\lambda_{\max }=665 \mathrm{~nm}\right)$.

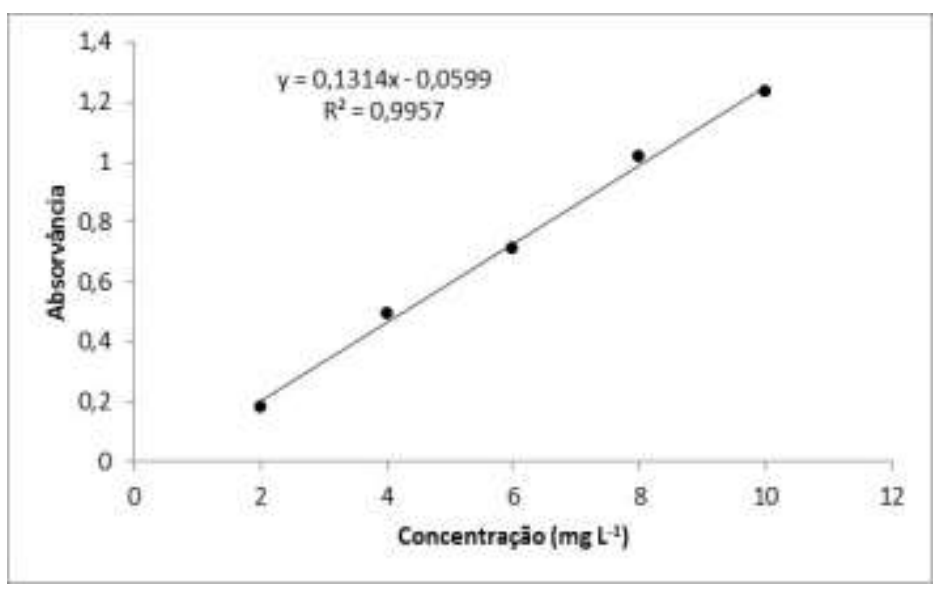

Fonte: Autores.

Para otimizar como seria o empacotamento do leito de adsorvente para a adsorção testou-se quatro diferentes metodologias:

A primeira a ser testada foi somente colocar o adsorvente, e adicionar o corante para a passagem até a saturação, porém observou-se que a coluna não ficava muito bem empacotada, e que assim o leito do adsorvente possivelmente se movimentava, ocasionando em uma adsorção não tão eficaz.

As próximas metodologias a serem testadas, utilizou-se algodão, a primeira colocando o algodão antes de ser adicionado o adsorvente, e outra logo após, nesse caso, ou seja, logo após o adsorvente constatou-se que o algodão respondia por uma parte da adsorção, dificultando a determinação correta da quantidade de corante que o adsorvente removia.

A quarta metodologia utilizada, e a escolhida para ser executada, foi utilizando pérolas de vidro após a montagem e empacotamento do leito com adsorvente, as pérolas de vidro tem a capacidade de diminuir o movimento das partículas do adsorvente, e por conseguinte o corante passe por igual no adsorvente, logo sendo esse o proposto da coluna de leito fixo, que o adsorvente fique empacotado da melhor forma possível, e que não ocorra movimento das partículas e também que passe por igual no leito.

Após a escolha da metodologia mais adequada, iniciou-se os testes com as biomassas escolhidas para julgar qual apresentava uma melhor adsorção.

O primeiro teste foi feito sem hidratar a biomassa escolhida, foi possível observar que sem a hidratação o processo de adsorção não era tão eficiente, pois o corante escoava mais entre a parede da coluna e o adsorvente e não pelo interior do adsorvente, comprometendo a eficiência.

Em seguida começou-se a hidratar as biomassas em água destilada por 30 minutos antes de fazer o empacotamento na coluna.

O primeiro adsorvente a ser testado foi casca de ovos $(1,5 \mathrm{~g})$, duas observações foram constatadas: primeiro que a vazão era extremamente lenta usando esse material, cerca de $0,02 \mathrm{~mL} \mathrm{~min}^{-1}$ e segundo que a adsorção praticamente não acontecia já que os primeiros volumes recolhidos da coluna já apresentavam concentração igual a solução inicial de azul de metileno. Portanto, cascas de ovos de galinhas não possui propriedades adsortivas de corantes azul de metileno.

O segundo adsorvente a ser testado foi a serragem de Mezilaurus itaúba $(1,5 \mathrm{~g})$, para esse material foi obtida uma vazão de $5 \mathrm{~mL} \mathrm{~min}^{-1}$, considerada boa, uma vez que não era demasiadamente lenta, ou seja, valores abaixo de $1 \mathrm{~mL} \mathrm{~min}^{-1}$, 
inviabilizando o processo, e nem muito rápida, cerca de $25 \mathrm{~mL} \mathrm{~min}^{-1}$, o que comprometeria a eficiência de adsorção. Sendo esses valores tido como referência para a coluna utilizada. $\mathrm{O}$ adsorvente mostrou-se eficaz na adsorção do azul de metileno, como podemos observar na Figura 2.

Figura 2. Curva de adsorção de azul de metileno em serragem de Mezilaurus Itaúba (massa = 1,5 g, $\mathrm{C}_{\mathrm{i}}=50 \mathrm{mg} \mathrm{\textrm {L } ^ { - 1 }}$ ).

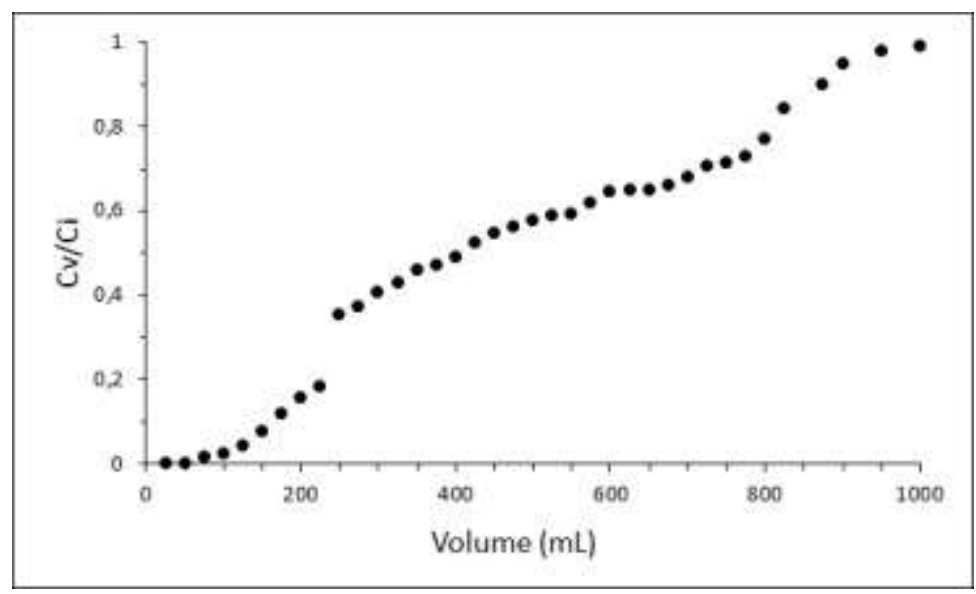

Fonte: Autores.

$\mathrm{O}$ ponto em que $\mathrm{C}_{\mathrm{v}} / \mathrm{C}_{\mathrm{i}}$ começa a ser diferente de zero é chamado de ponto de ruptura e determina em que momento começa a aparecer coloração no efluente da coluna, para a serragem de Mezilaurus itaúba o ponto de ruptura foi em $75 \mathrm{~mL}$, ou seja todo o azul de metileno presente em $50 \mathrm{~mL}$ de solução $50 \mathrm{mg} \mathrm{\textrm {L } ^ { - 1 }}$ foi removido por $1,5 \mathrm{~g}$ de serragem de Mezilaurus itaúba.

Após a saturação do adsorvente, ou seja, quando $\mathrm{Cv} / \mathrm{Ci}=1,0$, que aconteceu em torno dos $900 \mathrm{~mL}$ de solução, realizou-se a etapa de dessorção, que é a remoção do corante do adsorvente. Utilizou-se solução de $\mathrm{HCl} 1,0 \mathrm{~mol} \mathrm{~L}^{-1}$ para a dessorção pois o azul de metileno é um corante catiônico, logo há troca do corante por íons $\mathrm{H}_{3} \mathrm{O}^{+}$nos sítios ativos do adsorvente. A Figura 3 apresenta a curva de dessorção.

Figura 3. Curva de dessorção do azul de metileno retido em serragem de Mezilaurus itaúba.

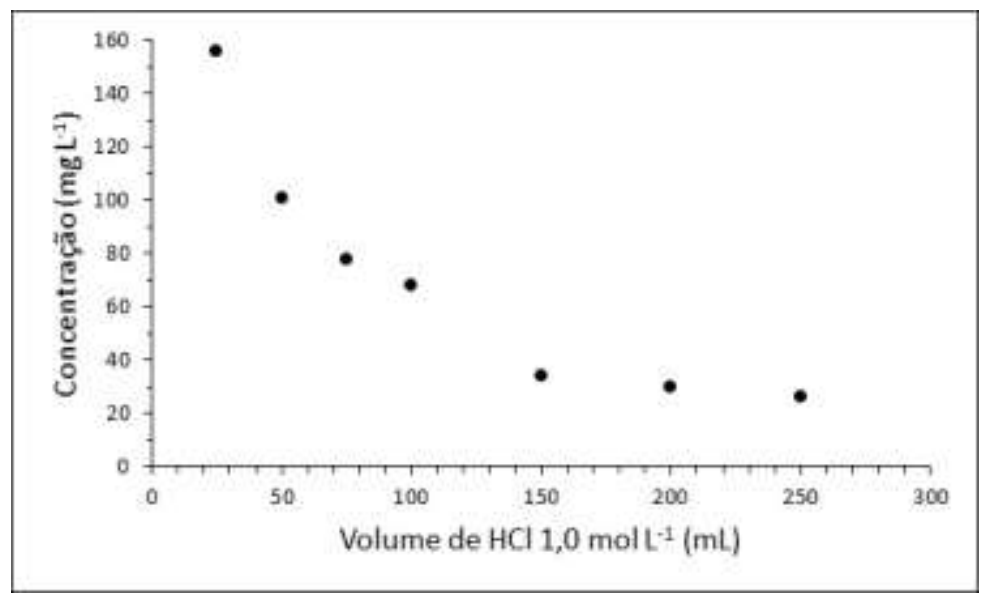

Fonte: Autores.

Observou-se que grandes concentrações de azul de metileno podem ser removidas já com $25 \mathrm{~mL}$ de $\mathrm{HCl}$ e que a concentração removida fica praticamente constante após $150 \mathrm{~mL}$ de $\mathrm{HCl}$. Portanto, foi possível recuperar o corante adsorvido. 
Para verificar se houve modificação da estrutura do corante após os processos de adsorção e dessorção, foram obtidos espectros de absorção na região do visível para o azul de metileno antes e após esses processos (Figura 4).

Figura 4. Espectro de Absorção do corante azul de metileno.

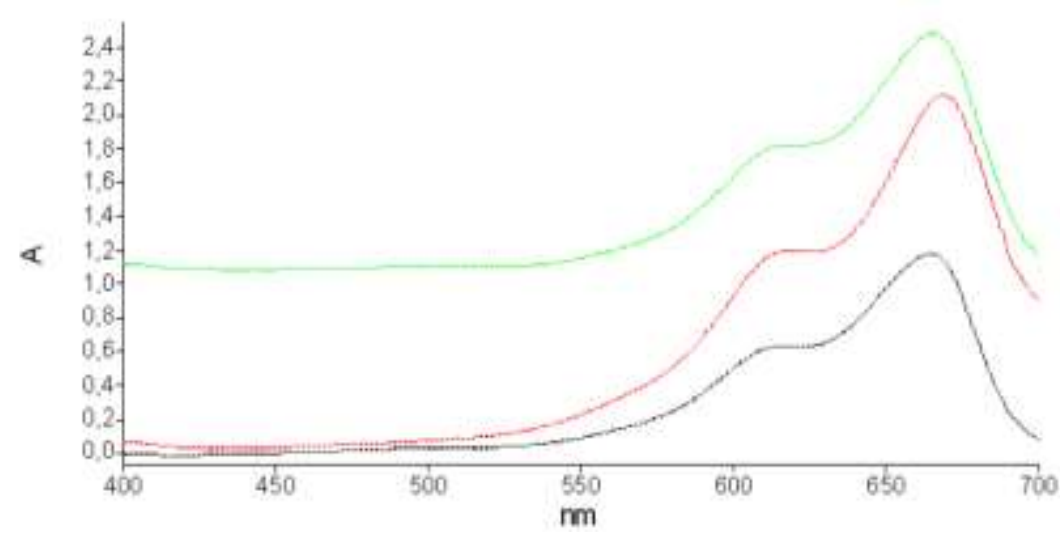

(Curva em preto: azul de metileno antes da adsorção; Curva em vermelho: azul de metileno após passagem pela coluna de serragem de Mezilaurus itaúba; Curva em verde: azul de metileno após dessorção com $\mathrm{HCl}$ 1,0mol L-1). Fonte: Autores (2021).

Observa-se que os padrões de absorção são os mesmos antes da adsorção, depois da adsorção e da dessorção, mostrando que não houve modificação da estrutura do corante, logo mesmo após a dessorção o corante poderá ser reutilizado, para a serragem do tipo Pinus elliotti o mesmo foi observado. A terceira biomassa a ser estudada foi a serragem de Pinus

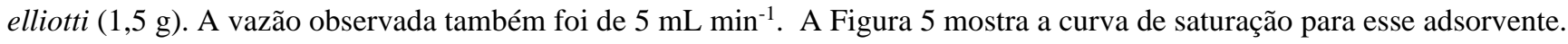

Figura 5. Curva de adsorção de azul de metileno em serragem de Pinus elliotti (massa $\left.=1,5 \mathrm{~g}, \mathrm{C}_{\mathrm{i}}=50 \mathrm{mg} \mathrm{L}^{-1}\right)$.

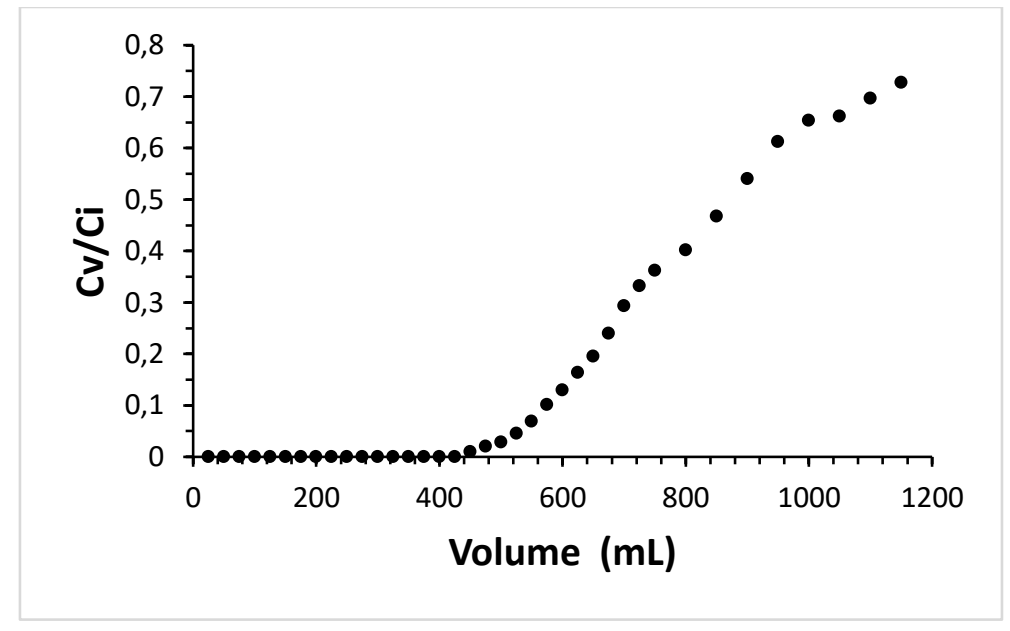

Fonte: Autores.

A serragem de Pinus elliotti mostrou-se mais eficiente do que a serragem de Mezilaurus itaúba, sendo o ponto de ruptura obtido somente depois da passagem de $425 \mathrm{~mL}$ da solução do corante, e a saturação ocorre somente em $1200 \mathrm{~mL}$. A dessorção foi realizada com solução de $\mathrm{HCl}$ 1,0 $\mathrm{mol} \mathrm{L}^{-1}$ e a curva obtida é apresentada na Figura 6. 
Figura 6. Curva de dessorção do azul de metileno retido em serragem de Pinus elliotti.

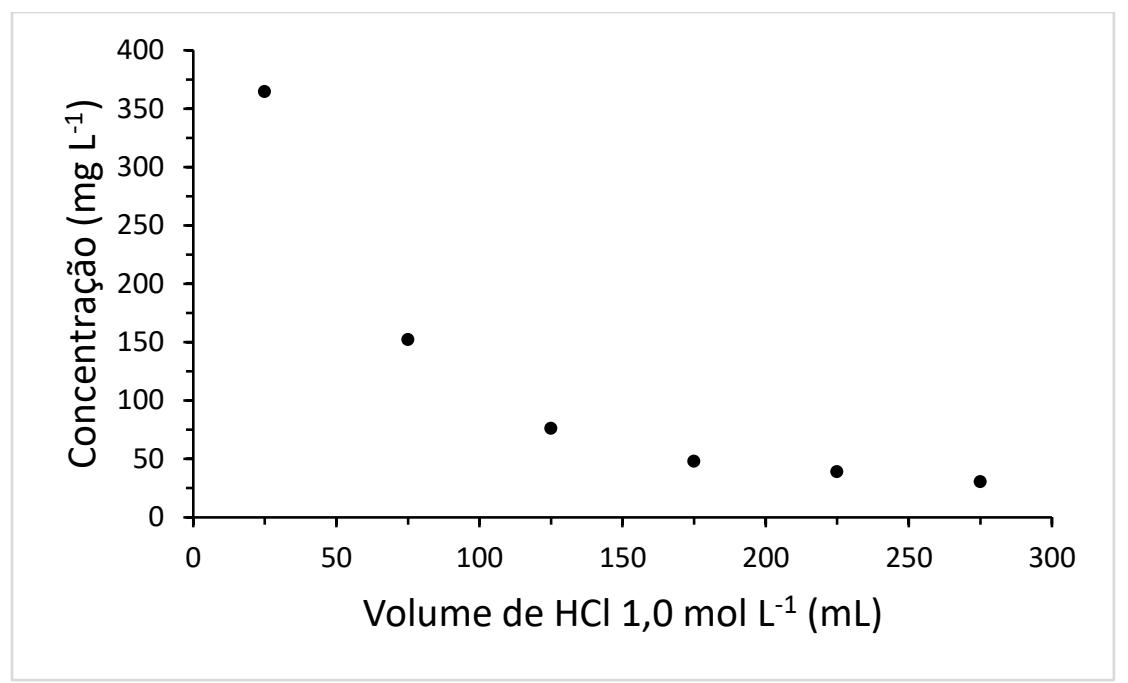

Fonte: Autores.

Como observado para a serragem de Mezilaurus itaúba o corante pode ser recuperado e a maior parte é removida com $75 \mathrm{~mL}$ de $\mathrm{HCl}$.

O último material a ser testado foi Citrus Sinensis, num primeiro momento pode-se observar que o tamanho das partículas do bagaço fazia com que a vazão da coluna fosse muito lenta usando a granulometria de $425 \mu \mathrm{m}$, portanto, outra granulometria maior foi testada, a de $600 \mu \mathrm{m}$, adotando a granulometria de $600 \mu \mathrm{m}$ para o estudo. Além da granulometria a massa de bagaço também foi variada de 2,0 a $0,7 \mathrm{~g}$. A Tabela 1 mostra a vazão obtida para cada massa de bagaço utilizada.

Tabela 1. Vazão em função da massa de Citrus Sinensis.

\begin{tabular}{cc}
\hline Massa $(\mathrm{g})$ & Vazão $\left(\mathrm{mL} \mathrm{min}^{-1}\right)$ \\
\hline 2,0 & $0,55 \pm 0,02^{\mathrm{e}}$ \\
1,5 & $0,78 \pm 0,03^{\mathrm{d}}$ \\
1,25 & $0,93 \pm 0,08^{\mathrm{c}}$ \\
1,0 & $1,25 \pm 0,05^{\mathrm{b}}$ \\
0,7 & $2,1 \pm 0,12^{\mathrm{a}}$ \\
\hline
\end{tabular}

Fonte: Autores.

A massa de bagaço utilizada na construção da curva de saturação foi de $0,7 \mathrm{~g}$, pois a vazão foi melhor para essa massa. A Figura 7 apresenta a curva de saturação para a adsorção de azul de metileno em bagaço de Citrus Sinensis. 
Figura 7. Curva de adsorção do azul de metileno em bagaço de Citrus Sinensis. (massa=0,7 g, $\mathrm{C}_{\mathrm{i}}=50 \mathrm{mg} \mathrm{L}^{-1}$ ).

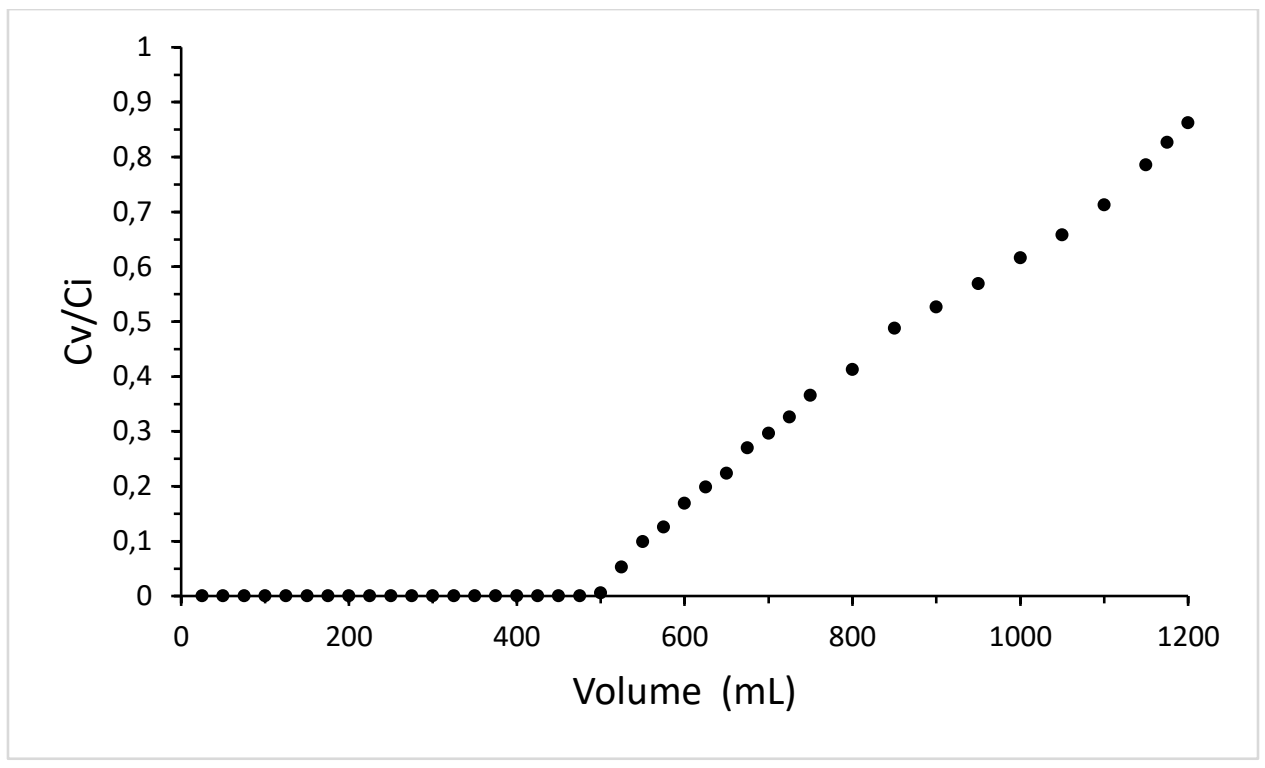

Fonte: Autores.

O bagaço de laranja se mostrou um ótimo adsorvente se comparado aos anteriores, já que com uma massa bem menor o ponto de ruptura foi em $525 \mathrm{~mL}$ de solução. A saturação ocorreu somente após a passagem de $1200 \mathrm{~mL}$ de solução. Os testes de dessorção não foram realizados com o bagaço de Citrus Sinensis porque a vazão se tornou extremamente lenta, cerca de 5 $\mathrm{mL} \mathrm{h}^{-1}$, após a passagem de $\mathrm{HCl}$, impossibilitando o estudo.

\subsection{Capacidade de adsorção}

A capacidade de adsorção do adsorvente presente em uma coluna, q $\left(\mathrm{mg} \mathrm{g}^{-1}\right)$, expressa a quantidade máxima de corante que pode ser adsorvido por g de adsorvente e pode ser determinada pela equação 1, (Veit, Silva, Fagundes-Klen, Tavares, \& Gonçalves, 2009).

$$
q=\frac{C_{i} \cdot Q}{m} \int_{0}^{t}\left(1-\frac{C v}{C i}\right) d t
$$

Onde:

$\mathrm{C}_{\mathrm{i}}$ é a concentração inicial do corante $\left(\mathrm{mg} \mathrm{L}^{-1}\right)$;

$\mathrm{C}_{\mathrm{v}}$ é a concentração do corante na saída da coluna $\left(\mathrm{mg} \mathrm{L}^{-1}\right)$;

Q é vazão $\left(\mathrm{L} \mathrm{min}^{-1}\right)$;

t é o tempo (min);

m é a massa de adsorvente $(\mathrm{g})$;

Para a determinação de q utilizou-se o software Origin 8 . Um gráfico de tempo (min) versus $\left(1-\mathrm{C}_{\mathrm{v}} / \mathrm{C}_{\mathrm{i}}\right)$ foi plotado e a área sobre o gráfico determinada. Essa área foi então multiplicada pelo fator $\mathrm{C}_{\mathrm{i}} \cdot \mathrm{Q} / \mathrm{m}$. A Figura 8 , mostra um exemplo da curva usada para a determinação de q do bagaço de Citrus Sinensis. 
Figura 8. Curva usada para a determinação da capacidade de adsorção do bagaço de Citrus Sinensis em sistema de coluna de leito fixo.

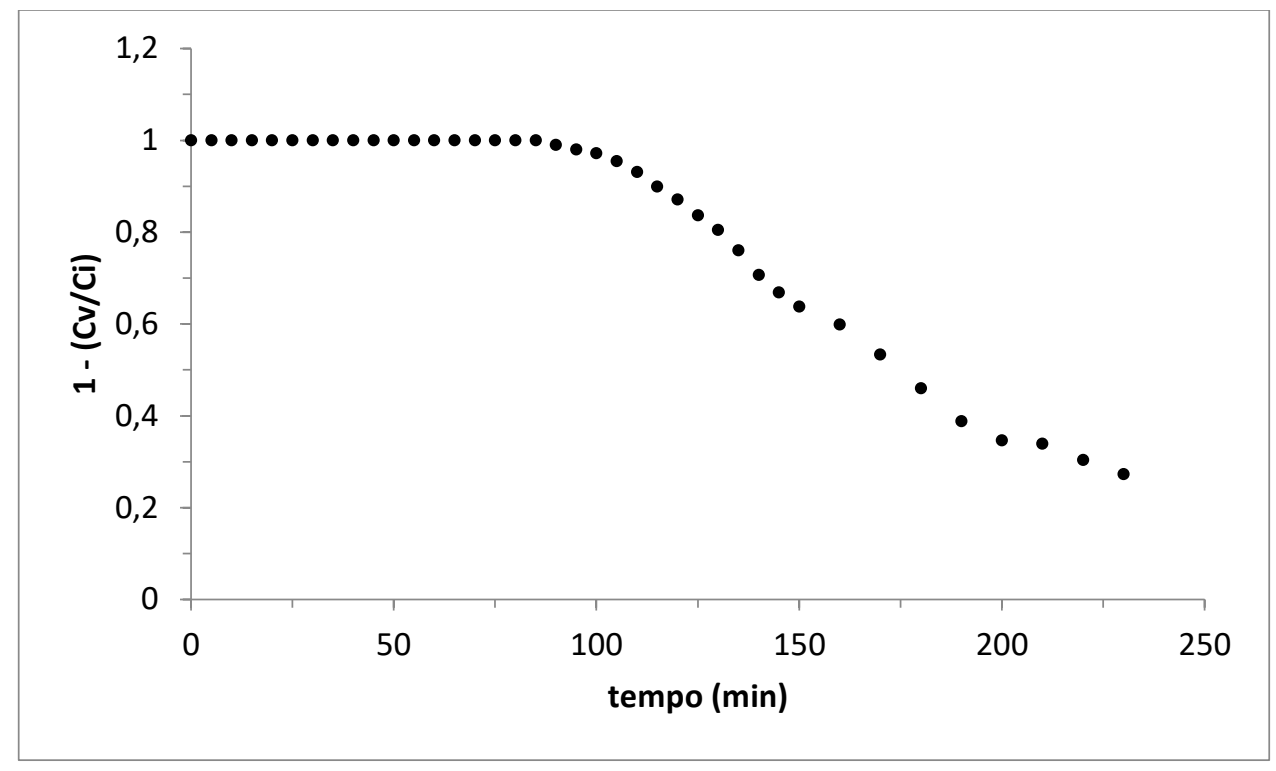

Fonte: Autores.

A Tabela 2 mostra os valores de q para os adsorventes estudados. Como observado por meio das curvas de saturação o material mais eficiente foi o bagaço de Citrus Sinensis, que apresentou capacidade de adsorção de 63,0 mg de corante por g de adsorvente, isso pode ser constatado na Tabela 2 abaixo.

Tabela 2. Capacidade de adsorção de azul de metileno por diferentes adsorventes

\begin{tabular}{cc}
\hline Adsorvente & Capacidade máxima de adsorção, $\mathbf{q},\left(\mathbf{m g ~ g}^{-\mathbf{1}}\right)$ \\
\hline Serragem de Mezilaurus Itaúba & 15,6 \\
Serragem de Pinus elliotti & 29,0 \\
Bagaço de Citrus Sinensis & 63,0 \\
\hline
\end{tabular}

Fonte: Autores.

\section{Conclusão}

A partir dos dados coletados, pode-se concluir que a melhor biomassa testada foi o bagaço de laranja, no entanto, sua aplicação ao sistema de coluna foi limitada pela vazão, sendo necessário para uma aplicação em larga escala de um sistema de pressão para auxiliar a percolação da solução. Fica evidente que a composição das biomassas influencia bastante no processo de adsorção, já que dois tipos diferentes de serragem apresentaram eficiência de adsorção bem distintas. A casca de ovos não apresentou propriedades adsortivas para o corante azul de metileno. Os estudos de adsorção em coluna são práticos, no entanto, podem ser demorados dependendo da estrutura e granulometria do adsorvente. Com isso trabalhos futuros devem ser desenvolvidos para avaliar outras biomassas para o tratamento de outros tipos de corantes, afim de tornar o processo de adsorção mais rápido, conveniente e de menor custo.

\section{Agradecimentos}

Os autores agradecem a Universidade Tecnológica Federal do Paraná - Campus Apucarana, Conselho Nacional de Desenvolvimento Científico e Tecnológico $(\mathrm{CNPq})$ e Coordenação de Aperfeiçoamento de Pessoal de Nível Superior 
(CAPES) pelo auxílio financeiro.

\section{Referências}

Abd, A. A., Naji, S. Z., Hashim, A. S., \& Othman, M. R. (2020). Carbon dioxide removal through physical adsorption using carbonaceous and noncarbonaceous adsorbents: a review. Journal of Environmental Chemical Engineering, 8, 104142.

Adeyiga, A. A., Hu, L., \& Greer, T. (1998). Removal of metal ions from wastewater with natural wastes. In Sixth Annual Historically Black Colleges and Universities and Other Minority Institutions Symposium, Ocean City, Maryland, United States.

Atkins, P. W., \& Paula, J. D. (1997). Físico-Química. 6a edição. Rio de Janeiro: LTC editora SA, 1, $190-214$.

Behera, M., Nayak, J., Banerjee, S., Chakrabortty, S., \& Tripathy, S. K. (2021). A review on the treatment of textile industry waste effluents towards the development of efficient mitigation strategy: an integrated system design approach. Journal of Environmental Chemical Engineering, 105277.

Castro, M. C., Alves, E. S., Saqueti, B. H. F., \& Montanher, S. F. (2021). Estudo de adsorção do corante Nylosan azul N-BLN têxtil em resíduos de semente de maracujá. Research, Society and Development, 10, e573101321594.

Cunico, P., Magdalena, C. P., Carvalho, T. E., \& Fungaro, D. A. (2009). Adsorção de corante reativo preto 5 em solução aquosa utilizando cinzas leves de carvão.

Fujisawa, R. S., \& Lamas, W. Q. (2011). Reuse of effluent from dyeing polyester fibers by thermal fixation using acid-based colors. Exacta, 9(2), 241-250.

Giannakoudakis, D. A., Hosseini-Bandegharaei, A., Tsafrakidou, P., Triantafyllidis, K. S., Kornaros, M., \& Anastopoulos, I. (2018). Aloe vera waste biomassbased adsorbents for the removal of aquatic pollutants: a review. Journal of environmental management, 227, 354-364.

Guilarduci, V. V. D. S., Mesquita, J. P. D., Martelli, P. B., \& Gorgulho, H. D. F. (2006). Adsorção de fenol sobre carvão ativado em meio alcalino. Química nova, 29, 1226-1232.

Hassemer, M. E. N., \& Sens, M. L. (2002). Tratamento do efluente de uma indústria têxtil. Processo físico-químico com ozônio e coagulação/floculação. Engenharia sanitária e ambiental, 7(1), 30-36.

Madhav, S., Ahamad, A., Singh, P., \& Mishra, P. K. (2018). A review of textile industry: Wet processing, environmental impacts, and effluent treatment methods. Environmental Quality Management, 27(3), 31-41.

Matiello, S. (2017). Avaliação da eficiência de um filtro de adsorção com carvão ativado na purificação de biogás proveniente da fração orgânica dos resíduos urbanos. [Dissertação (Mestrado). Fundação Universidade Federal de Rondônia, Porto Velho].

Minatti, T. C. D. S. (2020). Nanocompósito celulose bacteriana e hidroxiapatita para remoção de zinco de efluentes industriais. [Dissertação (Mestrado) Universidade Federal de Santa Catarina, Joinville].

Muharrem, I. N. C. E., \& Ince, O. K. (2017). An overview of adsorption technique for heavy metal removal from water/wastewater: a critical review. International Journal of Pure and Applied Sciences, 3, 10-19.

Oliveira, D., Giunti, O. D., Silva, A. V., da Silva Santos, C., Morais, M. A., da Silva, G. J., \& Rita, F. S. (2014). Aplicabilidade do reuso de água proveniente de processo industrial em beneficiamento têxtil. Poços de Águas Termais e Minerais, Poços de Calda.

Pereira, A. S., Shitsuka, D. M., Parreira, F. J., \& Shitsuka, R. (2018). Metodologia da pesquisa científica. UFSM. https://repositorio.ufsm.br/bitstream/handle/1/15824/Lic_Computacao_Metodologia-Pesquisa-Cientifica.pdf?sequence=1.

Rafatullah, M., Sulaiman, O., Hashim, R., \& Ahmad, A. (2010). Adsorption of methylene blue on low-cost adsorbents: a review. Journal of hazardous materials, $177,70-80$.

Silva, C. E. F., Gonçalves, A. H. S., \& Abud, A. K. S. (2016). Treatment of textile industry effluents using orange waste: a proposal to reduce color and chemical oxygen demand. Water Science and Technology, 74, 994-1004.

Tony, M. A. (2020). Zeolite-based adsorbent from alum sludge residue for textile wastewater treatment. International Journal of Environmental Science and Technology, 17, 2485-2498

Veit, M. T., Silva, E. A., Fagundes-Klen, M. R., Tavares, C. R. G., \& Gonçalves, G. C. (2009). Efeito da vazão volumétrica nas curvas de ruptura para o sistema de biossorção de Cr (III) e Ni (II). Estudos Tecnológicos em Engenharia, 5, 186-194. 